\title{
Impaired Memory Retrieval after Psychosocial Stress in Healthy Young Men
}

\author{
Sabrina Kuhlmann, Marcel Piel, and Oliver T. Wolf \\ Institute of Experimental Psychology, University of Duesseldorf, D-40225 Duesseldorf, Germany
}

Glucocorticoids (GCs) are known to modulate memory in animals and humans. One popular model suggests that stress or GC treatment enhances memory consolidation while impairing delayed memory retrieval. Studies in humans have documented that treatment with GCs impairs delayed memory retrieval. Similar alterations after exposure to stress have not been observed thus far. In the present study, 19 young healthy male subjects were exposed to either a standardized psychosocial laboratory stressor (Trier Social Stress Test) or a control condition in a crossover manner. After both treatments, retrieval of a word list (learned $24 \mathrm{~h}$ earlier) containing 10 neutral, 10 negative, and 10 positive words was tested. The stressor induced a significant increase in salivary free cortisol and a decrease in mood. Memory retrieval (free recall) was significantly impaired after the stress condition. Follow-up analysis revealed that negative and positive words (i.e., emotionally arousing words) were affected, whereas no effect was observed for neutral words. No changes were detected for cued recall, working memory, or attention. The present study thus demonstrates that psychosocial stress impairs memory retrieval in humans and suggests that emotionally arousing material is especially sensitive to this effect.

Key words: stress; steroid; memory; emotion; human; hippocampus

\section{Introduction}

Glucocorticoids (GCs) and catecholamines (adrenaline and noradrenaline) are secreted during stress to facilitate adaptation (De Kloet et al., 1998; McEwen, 1998; Sapolsky et al., 2000). In animals, stress hormones can have impairing as well as enhancing effects on memory (Lupien and McEwen, 1997; Sandi, 1998; De Kloet et al., 1999; Kim and Diamond, 2002; McGaugh and Roozendaal, 2002). Similarly, in humans, acute GC administration has beneficial or detrimental effects, depending on several modulatory variables (Lupien and Lepage, 2001; Wolf, 2003).

McGaugh and Roozendaal (2002) have established that increased levels of stress hormones lead to enhanced memory consolidation in rodents, which is in line with work by others (Sandi et al., 1997; Oitzl et al., 2001). However, stress as well as corticosterone treatment causes impaired delayed memory retrieval (de Quervain et al., 1998; Roozendaal, 2002). It appears that adrenergic activation in the basolateral amygdala and in the hippocampus is required for GCs to impair retrieval (Roozendaal et al., 2004b).

In humans, placebo-controlled pharmacological studies have observed that cortisol application leads to impaired memory retrieval (de Quervain et al., 2000, 2003; Wolf et al., 2001a; Buss et al., 2004). Whether similar effects occur after psychosocial stress is unknown. Previous human studies examined the effects of stress-induced cortisol elevations on learning and immediate re-

Received Dec. 16, 2004; revised Jan. 27, 2005; accepted Feb. 1, 2005.

This work was supported by German Research Foundation Grant W0 733/6-1. We thank Michael Cugialy, Sonja Meyer, and Gudrun Ramlow for conducting the laboratory stressor.

Correspondence should be addressed to Dr. Oliver T. Wolf, Institute of Experimental Psychology, University of Duesseldorf, Universitaetsstrasse 1, D-40225 Duesseldorf, Germany. E-mail: oliver.wolf@uni-duesseldorf.de. DOI:10.1523/JNEUROSCI.5139-04.2005

Copyright $\odot 2005$ Society for Neuroscience $\quad$ 0270-6474/05/252977-06\$15.00/0 call. Two studies observed memory impairments after stress (Payne et al., 2002; Jelicic et al., 2004), whereas most studies to date found no significant difference between the stress and the nonstress conditions (Kirschbaum et al., 1996; Wolf et al., 2001b; Domes et al., 2002; Takahashi et al., 2004). Several of the latter, however, observed associations between poorer memory and a stronger stress-induced cortisol increase within the treatment group (Kirschbaum et al., 1996; Wolf et al., 2001b; Takahashi et al., 2004). Only two studies have tested the effects of psychosocial stress on memory retrieval but failed to find significant effects, possibly for several reasons, which will be discussed later (Wolf et al., 2002; Domes et al., 2004).

Only recently, human glucocorticoid studies have started to consider the possible influence of emotional arousal or valence. Emotionally arousing material in general is better remembered than neutral material, and adrenergic activation in the amygdala seems to be responsible for this effect (Cahill, 2003; Strange and Dolan, 2004; van Stegeren et al., 2005). Therefore, several studies investigated whether the effects of glucocorticoids on learning/ memory are influenced by emotional arousal or valence. Two studies reported enhanced consolidation of emotionally arousing stimuli after cortisol or stress treatment (Buchanan and Lovallo, 2001; Cahill et al., 2003). Other experiments suggested that the immediate recall of positive and neutral but not of negative words was impaired by cortisol (Tops et al., 2003) or by stress (Jelicic et al., 2004). In contrast, a previous study from our group observed that delayed retrieval of negative but not of neutral words was impaired after oral cortisol (30 mg) treatment (Kuhlmann et al., 2005).

Because no previous stress study in humans was able to show impairing effects of stress on retrieval, the present experiment was conducted. In addition, we tested whether the emotional 
arousal of the learning material influenced the effects of stress on retrieval.

\section{Materials and Methods}

Nineteen young, healthy male university students between 19 and 40 years of age $(24.58 \pm 1.26)$ participated in this study. None of them suffered from any acute or chronic disease or took medication (selfreported). Presence of depression was screened with a German version of the Center for Epidemiological Studies Depression Scale (Hautzinger, 1993). The averaged body mass index of the subjects was $22.79 \pm 0.71$ $\mathrm{kg} / \mathrm{m}^{2}$. Each participant in this crossover study was tested in two experimental sessions (both of which consisted of 2 d; day 1, learning; day 2, treatment before retrieval) with a between-session interval of $\sim 4$ weeks. The study was approved by an ethics committee, and subjects provided written informed consent.

On the first day of each experimental session, participants arrived between 10:00 and 11:00 A.M. and learned a word list containing 10 positive, 10 neutral, and 10 negative words (for details, see below). On the following day, participants arrived at the laboratory at the same time and filled out a mood questionnaire (see below). Thirty minutes later, they took part in the Trier Social Stress Test (TSST) (Kirschbaum et al., 1993) or a control condition, both of which lasted $\sim 15 \mathrm{~min}$. Immediately after the treatment, the participants again filled out the mood questionnaire. Ten minutes after cessation of the stressor (i.e., at the time of peak cortisol levels), free and cued recall of the word list was tested. Thereafter, working memory and attention were assessed. The same procedure with the alternate treatment was repeated after $\sim 4$ weeks.

Stress and control treatment. Psychosocial stress in humans leads to elevated cortisol levels via activation of the hypothalamic-pituitary-adrenal (HPA) axis (Mason, 1968). In a laboratory context, the TSST is a well established and very efficient paradigm to induce a significant HPA response (Kirschbaum et al., 1993). A recent meta-analysis has revealed that in humans, social evaluative threat in combination with uncontrollability is associated with the largest cortisol increases in the laboratory (Dickerson and Kemeny, 2004). Both aspects are realized in the TSST. The TSST consists of a short preparation period $(2 \mathrm{~min})$, followed by a 5 min free speech (i.e., a fictitious job interview focusing on personal strengths and weaknesses) in front of a committee (i.e., one man and one woman wearing white coats), with an additional 5 min of mental arithmetic (i.e., counting backward from 2043 in steps of 17). In addition, the subjects are videotaped. The TSST has been shown to reliably induce a significant cortisol increase in plasma and saliva (Kirschbaum et al., 1993). The control condition consisted of a $5 \mathrm{~min}$ speech (about a movie or a book) and $5 \mathrm{~min}$ of mental arithmetic in an empty room (S. Het, S. M. Kern, N. Rohleder, C. Kirschbaum, and O. T. Wolf, unpublished observations). This control condition is relatively similar in physical and mental workload but lacks the stress-inducing components of the TSST, which are social evaluative threat and uncontrollability (Mason, 1968; Dickerson and Kemeny, 2004).

The tests and questionnaires used are discussed below.

Memory for words. A word list (with two parallel versions available) containing 10 positive, 10 negative, and 10 neutral words was presented to the subjects on a piece of paper. There were no differences among the positive, neutral, and negative words or between the two lists with respect to word frequency (norms were taken from a German internet database), word length, or semantic cohesion. Semantic cohesion was tested in 24 participants who did not participate in this study. They had to sort the words into groups with high inter-item associations (Miller, 1969). Emotionally arousing words often show a higher semantic cohesion than neutral words, and it is argued that some emotional effects are actually based on semantic cohesion rather than on emotional arousal (Maratos et al., 2000) [but see McNeely et al. (2004) for a divergent opinion]. In the current study, the two lists and the three categories did not differ with regard to semantic cohesion. Moreover, the two lists resulted in similar learning and delayed recall performance.

Subjects were given $2 \mathrm{~min}$ to learn the list, and immediate free recall was tested. This procedure was immediately repeated so that the subjects underwent two learning trials.

On the following day, delayed free recall of the words was tested $10 \mathrm{~min}$

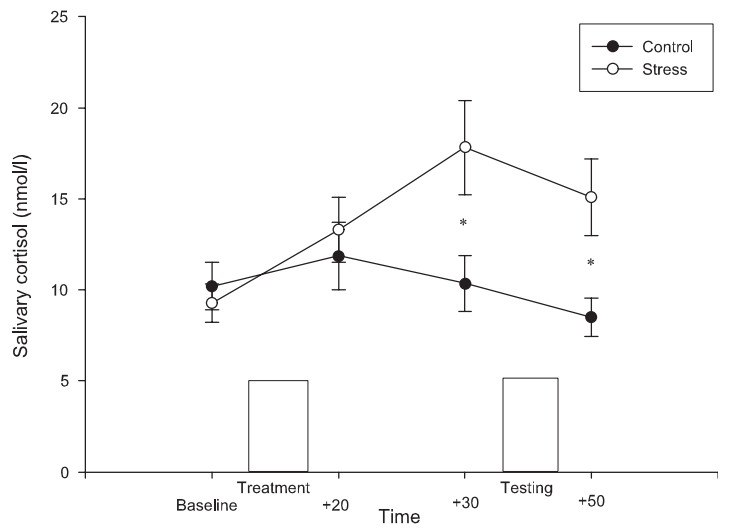

Figure 1. Free salivary cortisol levels in response to the stress or the control condition. "Treatment" refers to the stress versus the control condition (for details, see Materials and Methods). "Testing" refers to the period of retrieval and cued-recall testing (of the word list learned $24 \mathrm{~h}$ earlier) as well as to the working memory and attention testing. *Significant differences $(p<0.05)$ in Holm-adjusted paired $t$ tests. Error bars represent SE.

after the treatment (stress or control). To account for possible withinand between-subject variance in initial learning, free-recall performance on the treatment day was expressed as the percentage of words remembered in relation to the second (and last) learning trial on the learning day [similar to the study by Kuhlmann et al. (2005)].

Cued recall was assessed immediately after free recall by randomly presenting the first two letters of each learned word on a piece of paper, with instructions to complete the word stems with the previously learned words.

Working memory (digit-span test). Series of digits with increasing length were read to the subjects. They had to repeat each series. Each set length was tested twice. A forward and a backward condition was used. For each correctly repeated set, one point was given (Wechsler, 1987).

$d 2$ test of attention/psychomotor speed. From a series of the letters $\mathrm{d}$ and $\mathrm{p}$, with one or two lines above and/or below each letter, the participants had to mark the d's with two lines as quickly and correctly as possible. A summary test score was calculated using the number of correctly marked d's minus the number of errors (Brickenkamp, 1994).

Mood assessment. An adjective checklist containing 32 words for the assessment of bad versus good mood (16 items), alertness versus fatigue ( 8 items), and calmness versus restlessness ( 8 items) was used. The participants had to mark how much the words matched their current mood. The score for each item ranged from 0 to 5 , with higher numbers indicating a stronger agreement with the positive end of each scale. For ease of presentation, we divided the total score by the number of items so that the results from each scale also ranged from 0 to 5 (Steyer et al., 1994).

Saliva sampling and cortisol assessment. Saliva was collected using Salivette collection devices (Sarstedt, Nümbrecht, Germany). Samples were taken before the treatment (baseline), immediately after treatment ( $+1 \mathrm{~min})$, immediately before cognitive testing $(+10 \mathrm{~min})$, and after cognitive testing $(+30 \mathrm{~min})$. Free cortisol levels were measured using a commercially available immunoassay (Immuno-Biological Laboratories, Hamburg, Germany). Interassay and intra-assay variations were $<15 \%$.

Statistical analysis. Data were analyzed with paired $t$ tests or with ANOVAs for repeated measurements. Greenhouse-Geisser corrected $p$ values were used when indicated. Follow-up analysis of ANOVA effects was done using Holm-adjusted $t$ tests (Aickin and Gensler, 1996).

\section{Results}

\section{Cortisol levels}

Results revealed the expected stress-induced cortisol increase (Fig. 1). An ANOVA with the two repeated-measurement factors, treatment (stress vs control) and time (baseline, $+1,+10$, and $+30 \mathrm{~min})$, revealed a significant treatment by time interaction $\left(F_{(3,54)}=9.04 ; p<0.01\right)$. The Holm-adjusted paired $t$ test 


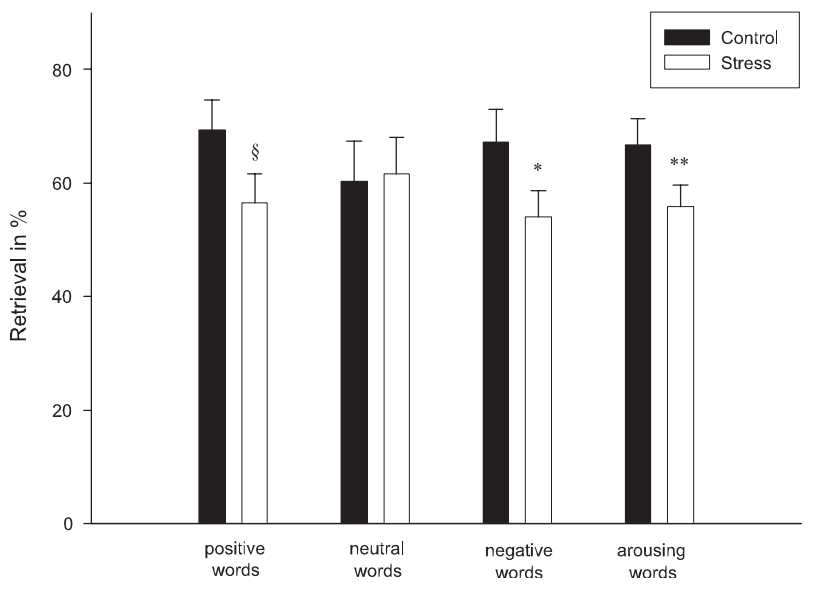

Figure 2. Effects of the stress versus the control condition on delayed memory retrieval of words learned $24 \mathrm{~h}$ earlier. Results are expressed as percentages of the second (and last) learning trial of the previous day. Each word list contained 10 positive, 10 neutral, and 10 negative words. The category "arousing words" is a post hoc created category containing the positive and the negative words. ${ }^{\S} p<0.1,{ }^{*} p<0.05$, and ${ }^{* *} p<0.01$, differences in paired $t$ tests. For additional statistical analysis using ANOVAs, see Results. Error bars represent SE.

Table 1. Results of the cognitive tests and the mood scale

\begin{tabular}{lrr}
\hline & Control condition & Stress condition \\
\hline First learning trail & $12.31 \pm 0.78$ & $12.58 \pm 0.73$ \\
Second learning trial & $18.26 \pm 1.15$ & $18.68 \pm 0.92$ \\
Cued recall & $13.47 \pm 1.41$ & $12.42 \pm 1.30$ \\
Digit-span forward & $8.63 \pm 0.43$ & $9.21 \pm 0.44$ \\
Digit-span backward & $7.89 \pm 0.43$ & $7.84 \pm 0.36$ \\
Attention test (correct hits minus errors) & $204.74 \pm 7.84$ & $214.58 \pm 8.12$ \\
Good versus bad mood (before treatment) & $3.90 \pm 0.15$ & $3.89 \pm 0.16$ \\
Good versus bad mood (after treatment) & $3.90 \pm 0.16$ & $3.62 \pm 0.16$ \\
\hline
\end{tabular}

All results are means \pm SE. For statistical analysis, see Results.

showed significantly elevated cortisol levels at $10 \mathrm{~min}\left(t_{(18)}=\right.$ $-2.74 ; p=0.01)$ and $30 \min \left(t_{(18)}=-2.79 ; p=0.01\right)$ after stress compared with the control condition.

\section{Memory retrieval}

Stress treatment led to a significant reduction in free recall of all of the words. In the TSST condition, subjects retrieved $56.80 \pm$ $4.01 \%$ of the words learned $24 \mathrm{~h}$ earlier but retrieved $64.17 \pm$ $4.76 \%$ in the control condition $\left(t_{(18)}=3.31 ; p<0.01\right)$. ANOVA with the factors treatment (stress vs control) and valence (positive, neutral, and negative) revealed a significant main effect of treatment $\left(F_{(1,18)}=9.46 ; p<0.01\right)$ but no significant treatment by valence interaction $\left(F_{(2,36)}=1.25 ; p=0.30\right)$. Explorative follow-up analysis with unadjusted paired $t$ tests showed that significantly fewer negative words were retrieved $\left(t_{(18)}=2.49\right.$; $p<0.02)$ in the stress condition compared with the control condition, whereas a trend in the same direction was observed for positive words $\left(t_{(18)}=1.98 ; p=0.06\right)$. Neutral words were not affected by stress $\left(t_{(18)}=-0.18 ; p<0.86\right)$. For means and SEs, see Figure 2.

Because of very similar results for negative and positive words, we created a new category, termed "arousing" words. In this group, negative and positive words were combined and averaged (Fig. 2). ANOVA with the factors treatment (stress vs control) and emotional arousal (arousing vs neutral) again revealed a significant main effect of treatment $\left(F_{(1,18)}=7.84 ; p=0.01\right)$, and this time a trend toward a treatment by arousal interaction $\left(F_{(1,18)}=\right.$ 3.75; $p=0.07)$ was observed as well. Follow-up analysis with
Holm-adjusted paired $t$ tests showed that significantly fewer emotionally arousing words were retrieved in the stress condition compared with the control condition $\left(t_{(18)}=3.61 ; p<0.01\right)$.

\section{Other cognitive measures}

Stress treatment had no effect on cued recall, working memory, or attention (all $p$ values $>0.10$ ). For means and SEs, see Table 1 .

\section{Subjective ratings}

Data were analyzed with ANOVAs with the factors treatment (stress vs control) and time (before and after treatment) separately for each of the three scales. For good versus bad mood, a significant treatment by time interaction was observed $\left(F_{(1,18)}=\right.$ 5.96; $p<0.05)$. Subjects reported decreased mood in response to the TSST but not in response to the placebo condition (Table 1). For the other two scales, no significant treatment by time interaction was apparent (all $p$ values $>0.10$; data not shown).

\section{Discussion}

The present study has two main findings, which will be discussed in turn. First, we observed that psychosocial stress impaired memory retrieval. Second, emotionally arousing words appeared to be more affected than neutral words.

For the first time, we show an impairing effect of psychosocial stress on memory retrieval in humans. This is in line with previous studies in animals (de Quervain et al., 1998; Woodson et al., 2003) as well as with pharmacological studies in humans (de Quervain et al., 2000, 2003; Wolf et al., 2001a; Buss et al., 2004). Because pharmacological studies in humans induced free salivary cortisol levels in the upper physiological range [e.g., between 40 and $100 \mathrm{nmol} / \mathrm{L}$ (Deinzer et al., 1997)], it is remarkable that the moderate cortisol increases observed in the current stress study were also associated with a retrieval deficit. It is possible that the stronger adrenergic activation after psychosocial stress is partially responsible for this effect, because GCs appear to interact with adrenergic mechanisms in the amygdala and hippocampus in causing retrieval impairment (Roozendaal et al., 2004b). The important role of the medial temporal lobe in mediating the GC-induced retrieval impairment is also supported by a human neuroimaging study (de Quervain et al., 2003). Further supporting this notion is the observation that, similar to our previous pharmacological study (Kuhlmann et al., 2005), we did not find a significant effect of stress on cued recall, which had a strong priming aspect (presentation of the word stem) in this study. Priming performance is not dependent on the hippocampal formation (Squire, 1992), and previous stress and cortisol studies failed to find significant effects of the treatment in those tasks (Kirschbaum et al., 1996; Lupien et al., 1997). Because multiple brain regions are involved in remembering (Buckner and Wheeler, 2001) and because multiple brain regions are affected by GCs (Belanoff et al., 2001; Lupien and Lepage, 2001), more human neuroimaging studies on this topic appear to be warranted.

Two previous studies examining the effects of social stress on memory retrieval in young participants did not find a significant effect of stress (Wolf et al., 2002; Domes et al., 2004). The first investigation had a very long ( 4 weeks) delay between learning and recall (Wolf et al., 2002). It might be that older memory 
traces are not as susceptible to the disturbing effects of stress as recent traces. In addition, the retrieval performance was very low (possible floor effect). The same problem occurred in a more recent investigation with a shorter delay (Domes et al., 2004). Less than $15 \%$ of the initially presented 60 words were retrieved $24 \mathrm{~h}$ later by the subjects.

Another aspect worth discussing is the circadian cortisol rhythm and the possibility that stress might have different effects depending on the time of day and its associated basal cortisol levels. Lupien et al. (2002) examined young participants in the morning (at the circadian peak) and the late afternoon (close to the nadir). In the morning, GC treatment caused a memory impairment, whereas GC treatment in the afternoon enhanced memory, as indirectly measured with reaction times. It is thought that these findings reflect an inverted U-shaped dose-response relationship between cortisol and memory and are caused by a different occupation of the two receptors for glucocorticoids (type 1 and type 2, respectively) (Diamond et al., 1992; Lupien and McEwen, 1997; Lupien et al., 2002). Our subjects were tested in the morning, a time when negative effects of cortisol elevations might prevail. Perhaps studies in the afternoon are less likely to detect negative effects of social stress on memory performance. This could be an alternative explanation for the absent effects of social stress on retrieval performance in the study by Domes et al. (2004). However, the fact that several pharmacological studies that were conducted in the afternoon observed a cortisol-induced retrieval impairment appears to argue against a major influence of time of day, at least in experiments with strong cortisol elevations (de Quervain et al., 2000, 2003; Buss et al., 2004).

In addition, participants in the two previous studies were not required to solve a task in the control condition (Wolf et al., 2002; Domes et al., 2004). It is therefore likely that the mental workload and the global activation differed substantially between the stress and control conditions. In the current study, subjects in the control condition had to give a talk and had to perform mental calculations (similar to the stress condition) but were not exposed to social evaluative threat and uncontrollability. In line with a recent meta-analysis, subjects did not show a cortisol response to this control condition (Dickerson and Kemeny, 2004).

The second major finding of our study is that emotionally arousing words appear to be more affected by stress than neutral words. In accord with a previous study by our group, negative words were more affected than neutral words (Kuhlmann et al., 2005). We hereby replicate our cortisol findings with a psychosocial stressor and extend the observation to positive words, which appeared to be similarly affected, although the single comparison with $t$ tests only revealed a trend ( $p=0.06$ ). Previous pharmacological studies in humans have not addressed the issue of valence or emotional arousal systematically. de Quervain et al. (2000, 2003) used word lists that consisted of items of varying arousal and valence intensities (D. J. de Quervain, personal communication), but no formal analysis on the impact of emotional arousal was performed. In the study by Wolf et al. (2001a), words were from a shopping list, which most likely varied in valence, depending on the taste and preferences of the individuals. A cautious interpretation of our findings is that the retrieval of emotionally arousing words appears to be more affected by stress than retrieval of neutral words if both word categories are presented within one word list. Future studies on this topic should obtain subjective arousal ratings [similar to the study by Buchanan and Lovallo (2001)] to relate individual arousal ratings to individual retrieval performance.

Two previous studies have observed enhanced consolidation of emotionally arousing material when compared with neutral material after cortisol or stress treatment (Buchanan and Lovallo, 2001; Cahill et al., 2003). This study, as well as our previous pharmacological study (Kuhlmann et al., 2005), found a stronger retrieval impairment for emotionally arousing words when compared with neutral words. Thus, the beneficial and detrimental effects of GCs might be especially pronounced for emotionally arousing material. In our current study, as well as in previous studies (Buchanan and Lovallo, 2001; Kuhlmann et al., 2005), the effects of cortisol were similar for positive as well as negative material, which suggests that emotional arousal rather than valence is the crucial aspect of the observed interactions. These observations are in accord with neuroimaging studies showing that the activity of the amygdala is associated with memory formation of arousing stimuli (Cahill et al., 1996; Canli et al., 2000), apparently independent of stimuli valence (Hamann et al., 1999; Kensinger and Corkin, 2004). Pharmacological functional magnetic resonance imaging studies have shown recently that this effect is dependent on $\beta$-adrenergic activation in the amygdala (Strange and Dolan, 2004; van Stegeren et al., 2005), thereby replicating the effects demonstrated in rats (McGaugh and Roozendaal, 2002; Roozendaal, 2002). However, the role of the amygdala in emotional memory retrieval is not as well understood (Taylor et al., 1998; Dolan et al., 2000; Smith et al., 2004; Strange and Dolan, 2004). More imaging studies are warranted that investigate the effects of stress or stress hormones on memory retrieval. The only study on this topic to date observed a reduced blood flow in the right posterior medial temporal lobe after cortisol treatment (de Quervain et al., 2003). The finding of the present study that retrieval of emotional material is especially impaired by stress or cortisol treatment might explain the recently reported beneficial effects of low-dose cortisol treatment on reexperiencing and intrusions in patients with posttraumatic stress disorder (Aerni et al., 2004).

The TSST caused a decrease in mood, which is an effect that does not occur in pharmacological studies with moderate cortisol doses (Wolf et al., 2001a; Buss et al., 2004; Kuhlmann et al., 2005). Experimental studies with mood induction have often observed that mood-congruent items are better remembered than incongruent items (Matt et al., 1992). In line with this concept are findings that tested the effects of stress on learning of words and observed impaired memory for neutral words but enhanced memory for negative words (Jelicic et al., 2004). In the current study, the opposite results occurred. Despite stress-induced negative changes in mood, subjects retrieved fewer negative (and positive) words, whereas no effect was detectable for neutral words. Thus, our findings cannot be explained by indirect effects mediated via mood, but rather seem to reflect the distinct effects of stress hormones on hippocampal-mediated retrieval, which are in opposition to the effects on consolidation (Roozendaal, 2002).

In this initial experiment, we decided to only investigate men, because previous work in animals (Luine, 2002; Conrad et al., 2004; Shors, 2004) and humans (Wolf et al., 2001b) has suggested that the effects of stress on memory might differ between the sexes. Moreover, the cortisol response to the TSST is modulated by menstrual cycle phase as well as by the use of oral contraceptives (Kirschbaum et al., 1999). Future studies will have to investigate the effects of sex and sex hormones systematically.

In summary, the present study reports for the first time a significant negative effect of acute stress on delayed memory retrieval in humans. Emotionally arousing words were more affected by stress than neutral words. Thus, moderate cortisol ele- 
vations in response to psychosocial stress, most likely in combination with activation of the autonomous nervous system, can lead to negative effects on retrieval that are similar to those seen with oral cortisol treatment. These findings appear to be of relevance for situations in which a person has to retrieve information under stress (e.g., in exam situations, in testimonies, or in important business situations). The potential to reduce or block the impairing effect of stress on retrieval using psychological or pharmacological interventions should be explored (Heffelfinger and Newcomer, 2001; Gaab et al., 2003; Roozendaal et al., 2004a,b).

\section{References}

Aerni A, Traber R, Hock C, Roozendaal B, Schelling G, Papassotiropoulos A, Nitsch RM, Schnyder U, de Quervain DJ (2004) Low-dose cortisol for symptoms of posttraumatic stress disorder. Am J Psychiatry 161:1488-1490.

Aickin M, Gensler H (1996) Adjusting for multiple testing when reporting research results: the Bonferroni vs Holm methods. Am J Public Health $86: 726-728$.

Belanoff JK, Gross K, Yager A, Schatzberg AF (2001) Corticosteroids and cognition. J Psychiatr Res 35:127-145.

Brickenkamp R (1994) Test d2: Aufmerksamkeits-Belastungs-Test; Handanweisungen. Göttingen, Germany: Hogrefe.

Buchanan TW, Lovallo WR (2001) Enhanced memory for emotional material following stress-level cortisol treatment in humans. Psychoneuroendocrinology 26:307-317.

Buckner RL, Wheeler ME (2001) The cognitive neuroscience of remembering. Nat Rev Neurosci 2:624-634.

Buss C, Wolf OT, Witt J, Hellhammer DH (2004) Autobiographic memory impairment following acute cortisol administration. Psychoneuroendocrinology 29:1093-1096.

Cahill L (2003) Sex-related influences on the neurobiology of emotionally influenced memory. Ann NY Acad Sci 985:163-173.

Cahill L, Haier RJ, Fallon J, Alkire MT, Tang C, Keator D, Wu J, McGaugh JL (1996) Amygdala activity at encoding correlated with long-term, free recall of emotional information. Proc Natl Acad Sci USA 93:8016-8021.

Cahill L, Gorski L, Le K (2003) Enhanced human memory consolidation with post-learning stress: interaction with the degree of arousal at encoding. Learn Mem 10:270-274.

Canli T, Zhao Z, Brewer J, Gabrieli JD, Cahill L (2000) Event-related activation in the human amygdala associates with later memory for individual emotional experience. J Neurosci 20:RC99(1-5).

Conrad CD, Jackson JL, Wieczorek L, Baran SE, Harman JS, Wright RL, Korol DL (2004) Acute stress impairs spatial memory in male but not female rats: influence of estrous cycle. Pharmacol Biochem Behav 78:569-579.

Deinzer R, Kirschbaum C, Gresele C, Hellhammer DH (1997) Adrenocortical responses to repeated parachute jumping and subsequent h-CRH challenge in inexperienced healthy subjects. Physiol Behav 61:507-511.

De Kloet ER, Vreugdenhil E, Oitzl MS, Joels M (1998) Brain corticosteroid receptor balance in health and disease. Endocr Rev 19:269-301.

De Kloet ER, Oitzl MS, Joels M (1999) Stress and cognition: are corticosteroids good or bad guys? Trends Neurosci 22:422-426.

de Quervain DJ, Roozendaal B, McGaugh JL (1998) Stress and glucocorticoids impair retrieval of long-term spatial memory. Nature 394:787-790.

de Quervain DJ, Roozendaal B, Nitsch RM, McGaugh JL, Hock C (2000) Acute cortisone administration impairs retrieval of long-term declarative memory in humans. Nat Neurosci 3:313-314.

de Quervain DJ, Henke K, Aerni A, Treyer V, McGaugh JL, Berthold T, Nitsch RM, Buck A, Roozendaal B, Hock C (2003) Glucocorticoid-induced impairment of declarative memory retrieval is associated with reduced blood flow in the medial temporal lobe. Eur J Neurosci 17:1296-1302.

Diamond DM, Bennett MC, Fleshner M, Rose GM (1992) Inverted-U relationship between the level of peripheral corticosterone and the magnitude of hippocampal primed burst potentiation. Hippocampus 2:421-430.

Dickerson SS, Kemeny ME (2004) Acute stressors and cortisol responses: a theoretical integration and synthesis of laboratory research. Psychol Bull 130:355-391.

Dolan RJ, Lane R, Chua P, Fletcher P (2000) Dissociable temporal lobe activations during emotional episodic memory retrieval. NeuroImage 11:203-209.
Domes G, Heinrichs M, Reichwald U, Hautzinger M (2002) Hypothalamicpituitary-adrenal axis reactivity to psychological stress and memory in middle-aged women: high responders exhibit enhanced declarative memory performance. Psychoneuroendocrinology 27:843-853.

Domes G, Heinrichs M, Rimmele U, Reichwald U, Hautzinger M (2004) Acute stress impairs recognition for positive words-association with stress induced cortisol secretion. Stress 7:173-181.

Gaab J, Blattler N, Menzi T, Pabst B, Stoyer S, Ehlert U (2003) Randomized controlled evaluation of the effects of cognitive-behavioral stress management on cortisol responses to acute stress in healthy subjects. Psychoneuroendocrinology 28:767-779.

Hamann SB, Ely TD, Grafton ST, Kilts CD (1999) Amygdala activity related to enhanced memory for pleasant and aversive stimuli. Nat Neurosci 2:289-293.

Hautzinger M (1993) Allgemeine Depressions-Skala: ADS. Weinheim, Germany: Beltz.

Heffelfinger AK, Newcomer JW (2001) Glucocorticoid effects on memory function over the human life span. Dev Psychopathol 13:491-513.

Jelicic M, Geraerts E, Merckelbach H, Guerrieri R (2004) Acute stress enhances memory for emotional words, but impairs memory for neutral words. Int J Neurosci 114:1343-1351.

Kensinger EA, Corkin S (2004) Two routes to emotional memory: distinct neural processes for valence and arousal. Proc Natl Acad Sci USA 101:3310-3315.

Kim JJ, Diamond DM (2002) The stressed hippocampus, synaptic plasticity and lost memories. Nat Rev Neurosci 3:453-462.

Kirschbaum C, Pirke KM, Hellhammer DH (1993) The "Trier Social Stress Test"- a tool for investigating psychobiological stress responses in a laboratory setting. Neuropsychobiology 28:76-81.

Kirschbaum C, Wolf OT, May M, Wippich W, Hellhammer DH (1996) Stress- and treatment-induced elevations of cortisol levels associated with impaired declarative memory in healthy adults. Life Sci 58:1475-1483.

Kirschbaum C, Kudielka BM, Gaab J, Schommer NC, Hellhammer DH (1999) Impact of gender, menstrual cycle phase, and oral contraceptives on the activity of the hypothalamus-pituitary-adrenal axis. Psychosom Med 61:154-162.

Kuhlmann S, Kirschbaum C, Wolf OT (2005) Effects of oral cortisol treatment in healthy young women on memory retrieval of negative and neutral words. Neurobiol Learn Mem 83:158-162.

Luine V (2002) Sex differences in chronic stress effects on memory in rats. Stress 5:205-216.

Lupien SJ, Lepage M (2001) Stress, memory, and the hippocampus: can't live with it, can't live without it. Behav Brain Res 127:137-158.

Lupien SJ, McEwen BS (1997) The acute effects of corticosteroids on cognition: integration of animal and human model studies. Brain Res Brain Res Rev 24:1-27.

Lupien SJ, Gaudreau S, Tchiteya BM, Maheu F, Sharma S, Nair NP, Hauger RL, McEwen BS, Meaney MJ (1997) Stress-induced declarative memory impairment in healthy elderly subjects: relationship to cortisol reactivity. J Clin Endocrinol Metab 82:2070-2075.

Lupien SJ, Wilkinson CW, Briere S, Menard C, Ng Ying Kin NMK, Nair NPV (2002) The modulatory effects of corticosteroids on cognition: studies in young human populations. Psychoneuroendocrinology 27:401-416.

Maratos EJ, Allan K, Rugg MD (2000) Recognition memory for emotionally negative and neutral words: an ERP study. Neuropsychologia 38:1452-1465.

Mason JW (1968) A review of psychoendocrine research on the pituitaryadrenal cortical system. Psychosom Med 30:576-607.

Matt GE, Vazquez C, Campbell WK (1992) Mood-congruent recall of affectively toned stimuli: a meta-analytic review. Clin Psychol Rev 12:227-255.

McEwen BS (1998) Protective and damaging effects of stress mediators. N Engl J Med 338:171-179.

McGaugh JL, Roozendaal B (2002) Role of adrenal stress hormones in forming lasting memories in the brain. Curr Opin Neurobiol 12:205-210.

McNeely HE, Dywan J, Segalowitz SJ (2004) ERP indices of emotionality and semantic cohesiveness during recognition judgments. Psychophysiology 41:117-129.

Miller GA (1969) A psychological method to investigate verbal concepts. J Math Psychol 6:169-191.

Oitzl MS, Reichardt HM, Joels M, De Kloet ER (2001) Point mutation in the mouse glucocorticoid receptor preventing DNA binding impairs spatial memory. Proc Natl Acad Sci USA 98:12790-12795. 
Payne JD, Nadel L, Allen JJ, Thomas KG, Jacobs WJ (2002) The effects of experimentally induced stress on false recognition. Memory 10:1-6.

Roozendaal B (2002) Stress and memory: opposing effects of glucocorticoids on memory consolidation and memory retrieval. Neurobiol Learn Mem 78:578-595.

Roozendaal B, de Quervain DJ, Schelling G, McGaugh JL (2004a) A systemically administered beta-adrenoceptor antagonist blocks corticosteroneinduced impairment of contextual memory retrieval in rats. Neurobiol Learn Mem 81:150-154.

Roozendaal B, Hahn EL, Nathan SV, de Quervain DJ, McGaugh JL (2004b) Glucocorticoid effects on memory retrieval require concurrent noradrenergic activity in the hippocampus and basolateral amygdala. J Neurosci 24:8161-8169.

Sandi C (1998) The role and mechanisms of action of glucocorticoid involvement in memory storage. Neural Plast 6:41-52.

Sandi C, Loscertales M, Guaza C (1997) Experience-dependent facilitating effect of corticosterone on spatial memory formation in the water maze. Eur J Neurosci 9:637-642.

Sapolsky RM, Romero LM, Munck AU (2000) How do glucocorticoids influence stress responses? Integrating permissive, suppressive, stimulatory, and preparative actions. Endocr Rev 21:55-89.

Shors TJ (2004) Learning during stressful times. Learn Mem 11:137-144.

Smith AP, Henson RN, Dolan RJ, Rugg MD (2004) fMRI correlates of the episodic retrieval of emotional contexts. NeuroImage 22:868-878.

Squire LR (1992) Memory and the hippocampus: a synthesis from findings with rats, monkeys, and humans. Psychol Rev 99:195-231.

Steyer R, Schwenkmezger P, Notz P, Eid M (1994) Testtheoretische Analysen des Mehrdimensionalen Befindlichkeitsfragebogens (MDBF). Diagnostica 40:320-328.

Strange BA, Dolan RJ (2004) $\beta$-adrenergic modulation of emotional memory-evoked human amygdala and hippocampal responses. Proc Natl Acad Sci USA 101:11454-11458.
Takahashi T, Ikeda K, Ishikawa M, Tsukasaki T, Nakama D, Tanida S, Kameda T (2004) Social stress-induced cortisol elevation acutely impairs social memory in humans. Neurosci Lett 363:125-130.

Taylor SF, Liberzon I, Fig LM, Decker LR, Minoshima S, Koeppe RA (1998) The effect of emotional content on visual recognition memory: a PET activation study. NeuroImage 8:188-197.

Tops M, van der Pompe G, Baas D, Mulder LJ, Den Boer JA, Meijman TF, Korf J (2003) Acute cortisol effects on immediate free recall and recognition of nouns depend on stimulus valence. Psychophysiology 40:167-173.

van Stegeren AH, Goekoop R, Everaerd W, Scheltens P, Barkhof F, Kuijer JP, Rombouts SA (2005) Noradrenaline mediates amygdala activation in men and women during encoding of emotional material. NeuroImage 24:898-909.

Wechsler D (1987) Wechsler memory scale-revised. San Antonio, TX: Harcourt Brace Jovanovich.

Wolf OT (2003) HPA axis and memory. Best Pract Res Clin Endocrinol Metab 17:287-299.

Wolf OT, Convit A, McHugh PF, Kandil E, Thorn EL, De Santi S, McEwen BS, de Leon MJ (2001a) Cortisol differentially affects memory in young and elderly men. Behav Neurosci 105:1002-1011.

Wolf OT, Schommer NC, Hellhammer DH, McEwen BS, Kirschbaum C (2001b) The relationship between stress induced cortisol levels and memory differs between men and women. Psychoneuroendocrinology 26:711-720.

Wolf OT, Schommer NC, Hellhammer DH, Reischies FM, Kirschbaum C (2002) Moderate psychosocial stress appears not to impair recall of words learned four weeks prior to stress exposure. Stress 5:59-64.

Woodson JC, Macintosh D, Fleshner M, Diamond DM (2003) Emotioninduced amnesia in rats: working memory-specific impairment, corticosterone-memory correlation, and fear versus arousal effects on memory. Learn Mem 10:326-336. 